\title{
Foresight and Roadmapping Methodology: Trends and Outlook
}

\author{
Yusuke Kishita \\ Associate Professor, School of Engineering, kishita@pe.t.u-tokyo.ac.jp \\ The University of Tokyo, 7-3-1, Hongo, Bunkyo-Ku, Tokyo 1138656, Japan
}

\begin{abstract}
7 his guest editorial article introduces the contextual and theoretical frameworks of foresight and futures studies' methodologies. Outstanding questions relating to methodological development are then addressed. This is followed by an introduction to five papers that make important methodological contributions. The article ends with a call for further research on the questions that have been identified but remain unanswered.
\end{abstract}

Keywords: futures; foresight; methodology; roadmapping; scenario; forecasting

$\mathrm{T}$ here is a growing need to support strategic decision-making in governments and organizations that consider future uncertainties. The field of futures and foresight ${ }^{1}$ [Glenn, Gordon, 2009; Popper, 2008a,b] include, but is not limited to backcasting, Delphi, forecasting, roadmapping, and scenarios. The application of these methods in Science, Technology, and Innovation (STI) policy is utilized globally [Miles, 2010]. Each method provides a structured way of collecting information and generating knowledge about the future as opposed to either guessing or gazing into a crystal ball or predicting the future through a black box [ van der Duin, 2016]. Other reviews of relevant methods are provided elsewhere [Bishop et al., 2007, Glenn, 2009b; Gordon et al., 2020; Popper, 2008a,b].

Historically the field of futures and foresight has been led by practitioner-focused approaches, with comparatively little effort given to theory and methodology development [Fergnani, Chermack, 2021; Kishita et al., 2021; Wilkinson, 2009]. Unlike the natural sciences, there is tremendous variance in methods and tools. There is less systematization on futures and foresight processes and activities (e.g., how to choose an appropriate method to address the problem being considered). Nonetheless, the value of theory is acknowledged in the futures and foresight community. For both a fundamental understanding and to encourage the adoption and implementation of these approaches, the wide dissemination
Citation: Kishita Y. (2021) Foresight and Roadmapping Methodology: Trends and Outlook. Foresight and STI Governance, 15(2), 5-11. DOI: 10.17323/2500-2597.2021.2.5.11

of these futures and foresight methods should be facilitated in society to efficiently train people who are less experienced but want to use such methods in practice.

The fundamental questions raised in this issue are: (1) What methods are the state-of-the-art and (2) what challenges need to be tackled to advance methodology development? This article reviews selected futures and foresight methods, particularly focusing on forecasting, scenarios, and roadmapping. A framework for a better understanding of generalized futures and foresight processes is provided to formulate research questions to further the development of theory and methodology. Finally, how the five papers that constitute this special issue contribute to methodological development is considered.

This section focuses on the methods most typically utilized: scenarios, forecasting, roadmapping, and backcasting.

\section{Taxonomy of Futures}

Summarizing from different taxonomies, futures can be classified as follows [Börjeson et al., 2006, Hancock, Bezold, 1994; Voros, 2003]:

- Probable futures: refer to futures that are likely to happen by extrapolating current trends.

- Possible futures: refer to the widest range of futures that might happen based on currently available knowledge

${ }^{1}$ The term futures and foresight includes foresight, futures studies, futures research, and futurology. 


\section{Figure 1. Matching types of futures and foresight methods}

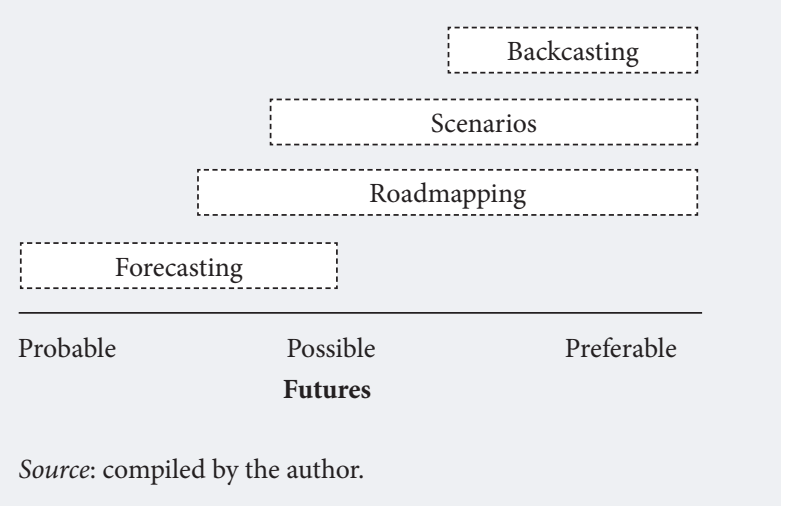

and people's imagination (i.e., new knowledge about the future). Considered as part of possible futures, plausible futures refer to futures that could happen based on currently available knowledge about the future. Preferable futures: refer to normative futures that are desired based on individual and collective values.

As depicted in Figure 1, different methods are chosen depending on which type of future is considered [Popper, 2008a; van der Duin, 2016]. Forecasting centers on predicting the most likely future. Roadmapping cuts across all types of futures as it emphasizes a process to describe pathways to any kind of future. Scenarios deal primarily with possible and preferable futures because scenarios are not predictions. It should be mentioned that scenarios may include probable futures often described as either baseline or Business-as-Usual (BaU) scenarios. Backcasting describes normative futures including preferable futures and sometimes dystopian or collapsed futures.

Figure 2. Number of articles published in the period of 2000-2020, with "foresight" or "futures" in their titles, abstracts, or keywords

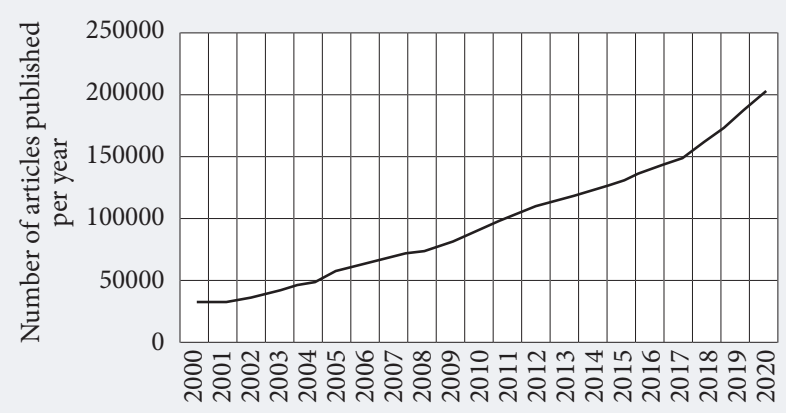

Source: compiled by the author based on Scopus search 20 March 2021.

\section{Key Futures and Foresight Methods}

A Scopus search for the words "foresight" or "futures" in article titles, abstracts, or keywords referenced approximately 200,000 articles in 2020. This is six times larger than the number of articles in 2000 (Figure 2). Figure 3 summarizes the articles into four categories: "scenarios," "forecasting," "roadmap or roadmapping," and "backcasting". In 2020, articles about scenarios account for approximately $5 \%(\sim 10,000)$ of the total number $(\sim 200,000)$ and those about forecasting come second (approximately 3\%). In contrast, fewer articles about roadmapping and backcasting are found. The number of roadmapping articles published in 2020 reached around 700, increasing 10 times from the number in 2000. Backcasting articles increased after the mid-2000s but are still minor in terms of the number of published articles ( 30 in 2020).

\section{Forecasting}

Forecasting consists of both qualitative and quantitative methods. The former includes the Delphi method and text mining. The latter includes trend extrapolation and econometric methods [Armstrong, 2001; Glenn, 2009b; Martino, 1993; Popper, 2008a]. Forecasting methods may focus on technology forecasting [Gerstenfeld, 1971; Martino, 1993]. A brief review of the most frequently used forecasting methods - Delphi method and trend extrapolation - is provided.

The Delphi method. Originally developed for military operations by RAND in the 1950s, the Delphi method is a useful way of assessing expert judgment ${ }^{2}$. Respondents (experts) are independently interrogated using questionnaires iteratively (e.g., two or three rounds), aimed at reaching a consensus on future technological developments [Linstone, Turoff, 1975; Gordon, 2009]. The selection of respondents is the key to a successful Delphi study [Gordon, 2009]. Over the last fifty years, the method has been used by many academics and practitioners [Rowe, Wright, 2011]. Since 1969, Japan has utilized large-scale Delphi surveys involving experts in a wide range of fields to support science and technology policy governance [Kuwahara, 1999; Kuwahara et al., 2008]. Urashima et al. [Urashima et al., 2012] reviewed the results of the Delphi surveys conducted between 1971 and 1992 . They found that approximately $70 \%$ of the topics under review had been achieved. The Delphi method is often combined with other techniques. For example, enhancing insights into scenarios [Wright et al., 2013]. This includes the work by [Chen et al., 2020; Culot et al., 2020; von der Gracht, Darkow, 2010; Wright et al., 2013].

Trend extrapolation is a quantitative forecasting tool. Extrapolation is based on historical data. Diverse variables are utilized. Examples include GDP per capita, life expectancy, and energy demand. Trend extrapolation is often applied to technology diffusion. Rogers' [Rogers, 2002] work on diffusion of innovation theory assumes

${ }^{2}$ https://www.rand.org/topics/delphi-method.html, accessed 20.03.2021. 


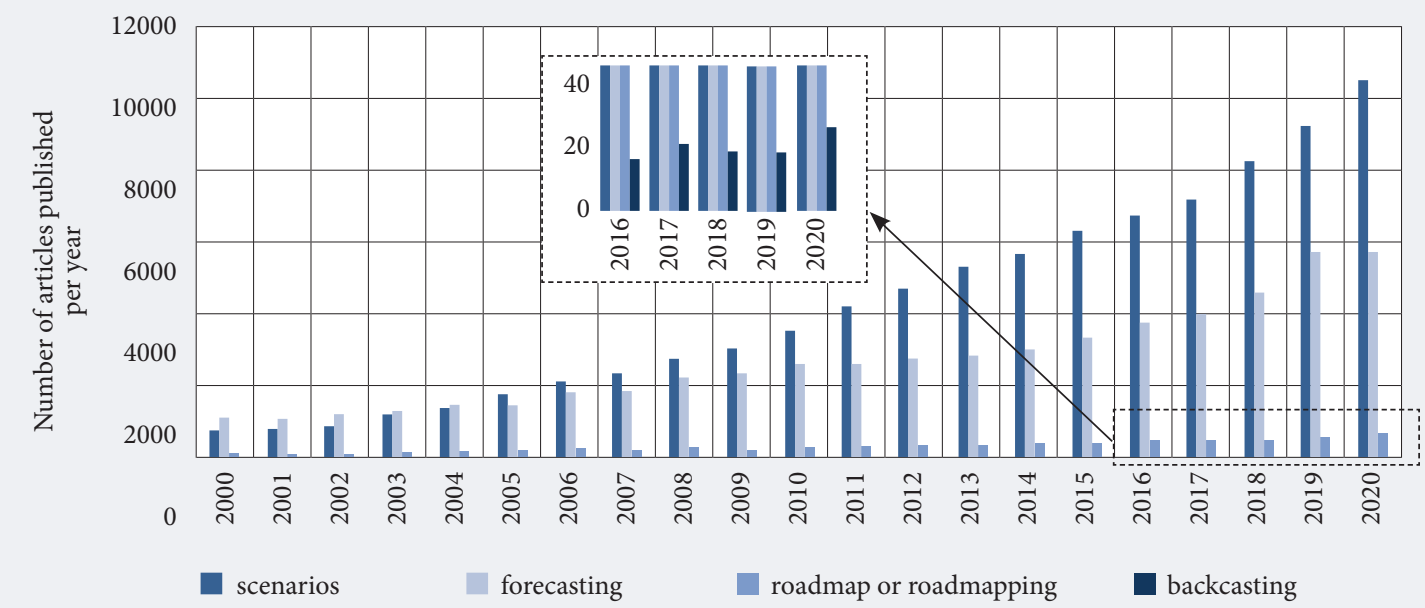

Source: compiled by the author based on Scopus search 20 March 2021.

that the adopters are classified into five categories (innovators, early adopters, early majority, late majority, and laggards). The cumulative adoption of a new technology over time is described as an S-curve [Gerstenfeld, 1971; Meade, Islam, 2006; Rogers, 2002].

Forecasting technology diffusion is dominated by the Bass model [Bass, 1969]. Bass assumes that adopters are influenced by two factors: (1) a desire to innovate and (2) imitation of others. The model estimates the fraction of adopters in a given year. This model is frequently modified, refined, and/or extended (e.g., [Fan et al., 2017; Seol et al., 2012]).

\section{Scenarios}

A scenario is a "hypothetical sequence of events leading to a possible future" [Kahn, Wiener, 1967]. Scenarios have been used to support decision making under uncertainty since the 1950s. Royal Dutch Shell utilized scenario analysis to better manage the first oil crisis (1970s). Since then, scenario planning is a popular corporate strategic decision-making tool [Wack,1985]. A number of different approaches are taken to consider the role of scenarios. Examples include (1) the scenario as a story with plausible cause and effect links that connect a future condition with the present [Glenn, 2009a] and (2) scenarios that are not about predicting the future but rather perceive the futures in the present [Schwartz, 1991]. Most scholars agree that scenarios are not predictions, but descriptors of possible futures that allow for a better understanding of the influence of uncertainties [Kishita et al., 2016, Spaniol, Rowland, 2019]. The most essential characteristic of scenarios is to provide possible alternative futures in a narrative format, helping stakeholders share a common understanding of and think about the future [Spaniol, Rowland, 2019; van Notten et al., 2003].

The scenario literature [Amer et al., 2013; Bishop et al., 2007; Kishita et al., 2016] offers a wide variety of methods and techniques. This has been described as a "methodological chaos" [Bradfield et al., 2005; Martelli, 2001]. The most prevalent method is to use a $2 \times 2$ matrix (i.e., four scenarios) considering the two most critical uncertainties from the external factors [Ogil$v y$, Schwartz, 1998]. One typical way of classification is forecasting or backcasting scenarios, these differ in terms of the vantage point [Börjeson et al., 2006; van Notten et al., 2003]. Forecasting scenarios describe possible futures that might unfold with the present as the starting point. Backcasting, however, describes desirable/undesirable future endpoints (visions) first, after which the paths from the future are drawn back to the present [Börjeson et al., 2006; Quist, Vergragt, 2006]. In both cases, a number of scenario development processes have been proposed [Kishita et al., 2016].

\section{Roadmapping}

Roadmapping is defined as a structured, temporal, and often graphical way of representing and exploring the dynamic linkages between technological resources, organizational objectives, and the changing environment [Phaal et al., 2004]. Since its introduction by Motorola in the 1970s, technology roadmapping is widely used to support strategy planning and product development at organizations [Willyard, McClees, 1987]. It is also applied in sectoral and STI policy contexts [Carayannis et al., 2016; Yasunaga et al., 2009]. Technology roadmaps show the time dimension, often using multiple layers to represent the relationships between markets, goods, services, and technologies [Phaal et al., 2004]. As roadmaps can take a variety of formats, they are designed to be suitable for specific purposes and contexts [Phaal et al., 2010].

A number of roadmap development methods are in use [de Alcantara, Martens, 2019; Park et al., 2020; Vatananan, Gerdsri, 2012]. Roadmapping is usually combined with workshops to promote communication, sharing, 


\section{Figure 4. A generalized futures and foresight process}

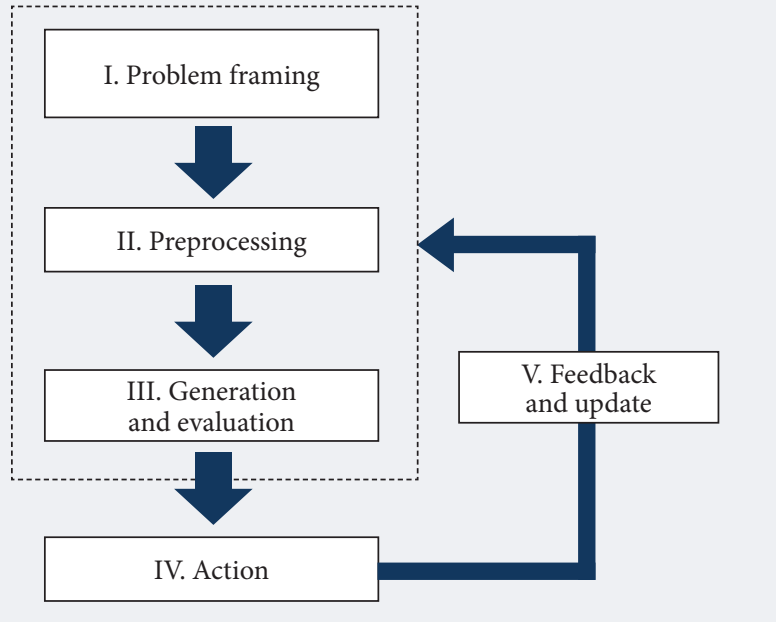

Source: compiled by the author basing on [Popper, 2008b; Voros, 2003].

and generating knowledge amongst stakeholders. For example, the T-Plan process supports product planning using a standard option to fast-track the roadmap implementation process at an organization [Phaal et al., 2003]. By extending the T-Plan process, value-driven technology roadmaps can integrate decision-making and marketing [Fenwick et al., 2009]. For example, Daim and Oliver [Daim, Oliver, 2008] present a framework for implementing technology roadmaps in the energy sector.

An emerging area is combining roadmaps with datadriven approaches to consider the dynamics of the competitive environment [Geum et al., 2015; Pora et al., 2020]. Some scholars have proposed integrating roadmapping and scenarios to assess the influence of future uncertainties [Hussain et al., 2017; Lee, Geum, 2017; Saritas, Aylen, 2010; Siebelink et al., 2016]. Integration increases the roadmap's robustness, thereby, providing better support for decision-making.

\section{Advancing Methodological Development in Futures and Foresight}

Futures and foresight are interdisciplinary and transdisciplinary activities involving diverse knowledge bases to address complex problems at organizations or in society [Kishita et al., 2021]. Figure 4 illustrates a generalized futures and foresight process that generates, evaluates, and manages knowledge about the future through the involvement of researchers, practitioners, and stakeholders. Each process step is briefly described in Table 1 . A participatory approach (using workshops involving experts and stakeholders) is often used to run the process.

While there are many methods to generate knowledge about the future, there are many questions related to methodology development that need further consideration:

- To what extent can digital technologies, artificial intelligence (AI), and other data-driven approaches support and enhance futures and foresight activities?

- What are the prerequisites for maximizing the benefits of utilizing the outputs of futures and foresight activities in order to solve the problem being addressed?

- Which part of the futures and foresight process can be more diversified and personalized to reflect needs in society and/or on the market? Exactly how will this be achieved?

- To what extent can the outputs of futures and foresight activities be evaluated before implementation (i.e., prior to Step IV)?

- How can decision-making be supported in a more agile and appropriate manner? How is this impacted by market competitiveness?

- As sustainability is increasingly important, what sort of methods and techniques help to generate useful knowledge to cover a longer time horizon (e.g., 2050 or 2060)?

- How should futures and foresight methods be adjusted or adapted in the future due to the impacts of

Table 1. Stages of futures and foresight process

\begin{tabular}{|l|l|}
\hline \multicolumn{1}{|c|}{ Stage } & \multicolumn{1}{c|}{ Description } \\
\hline I. Problem framing & $\begin{array}{l}\text { Defining the objective to be addressed, while specifying the theme/domain to be investigated, } \\
\text { the spatial and temporal boundary of concern, and who is to be involved. }\end{array}$ \\
\hline II. Preprocessing & $\begin{array}{l}\text { Preparing for knowledge generation by selecting methods to be used (e.g., forecasting, } \\
\text { scenarios, and roadmapping), collecting data from external sources (e.g., literature, websites, } \\
\text { and interviews), determining the detailed process, and recruiting workshop participants. }\end{array}$ \\
\hline III. Generation and evaluation & $\begin{array}{l}\text { Generating knowledge about the future, delineating possible futures based on collected data and } \\
\text { generated knowledge, and evaluating these futures. }\end{array}$ \\
\hline IV. Action & $\begin{array}{l}\text { Adopting the outputs of Step III to support decision-making, strategy planning, and } \\
\text { policymaking. }\end{array}$ \\
\hline V. Feedback and update & $\begin{array}{l}\text { Feedback to one or more of Steps I-III based on Step IV results. Updating or improving based } \\
\text { on the additional insights. }\end{array}$ \\
\hline Source: compiled by the author. & \\
\hline
\end{tabular}


COVID-19 (given that the pandemic has caused a drastic change in people's workstyles relating to the use of virtual environments)?

Recent developments in digital technologies and Artificial Intelligence (AI) allow a huge amount of relevant data and insight to be accessed efficiently [Gordon et al., 2020]. Some scholars are using these technologies for futures and foresight activities. Examples include text mining [Kayser, Blind, 2017; Ozcan et al., 2021], web mining [Kayser, Shala, 2020, Kehl et al., 2020], machine learning [Zhou et al., 2020], and graph theory [Kishita et al., 2020]. Gordon et al. [Gordon et al., 2020] note the blending of AI-generated and human-generated insights and their impact on decision-making is an interesting question for case studies in organizations. Also worth noting is that stakeholder engagement has recently been considered in the futures and foresight context using an action research approach [Gattringer, Wiener, 2020; Lehoux et al., 2020].

\section{Filling the Gap between Methodological Challenges and the Current Status}

The five papers in this special issue contribute to methodological development in the field, tackling a number of the questions raised above.

Daim et al. in the paper 'Forecasting Technology Trends through the Gap Between Science and Technology: The Case of Software as an E-Commerce Service' focus on technology forecasting to identify technology trends. This offers important help to companies to define potential markets for innovative products and services. They apply text mining techniques with expert judgment to a technology forecasting methodology. Drawing on scientific papers and patent information as data sources, text mining reveals trends in Software as a Service (SaaS) technology. Through gap analysis (scientific papers vs. patents), five technological trends are identified. The proposed method is widely applicable to the needs of stakeholders in industry, government, and academia.

Velasco et al. in the paper 'Repositioning People in Creative Futures: A Method to Create Sound Advice with Exploratory Scenarios' investigate how advice and recommendations are generated from scenario development. They analyze the influence of different future scenarios on the process of making recommendations. This is achieved by undertaking a deep analysis of scenario workshops on the future of the European Research Area (ERA). They find that it is valuable to reposition participants in transformative scenarios where in doing so participants situate their views in a hypothetical future context to make decisions contributing to the fluency and creativity of ideas.

Lee et al. in the paper 'Roadmapping in the Era of Uncertainty: How to Integrate Data-Driven Methods with Expert Insights' utilize 10 years of technology planning related to the noise, vibration, and harshness (NVH) of automobiles to illustrate an integrated data-driven and expert-based approach to roadmapping to better support decision-making related to STI. They develop a workshop-based roadmapping process consisting of three stages, i.e., ideation, selection, and planning. Data analysis during the workshop process supports idea generation and evaluation. The data inputs (patents and scientific publications) help experts generate, identify, and evaluate more ideas based on trend analysis both within and external to the sector.

Murata et al. in the paper 'Knowledge Co-Creation Roadmapping for Future Industrial Visions: a Case Study of Smart Infrastructure' integrate an organizational knowledge creation process model. More specifically, they introduce a Socialization-ExternalizationCombination-Internalization (SECI) model (Nonaka 1990) into roadmapping to promote knowledge sharing and generation among multiple stakeholders. New knowledge is generated through the interaction of tacit and formal knowledge as participants move through the four steps of: socialization, externalization, combination, and internalization. By iterating through the four steps, Murata et al. demonstrate the value of the method as a communication tool in developing a roadmap for smart social infrastructure enabling collective knowledge creation.

O'Sullivan et al. in the paper 'Agile Roadmapping: an Adaptive Approach to Technology Foresight' focus on the challenge of the limited guidance in ensuring roadmap outputs that are strategically relevant, appropriately detailed, and credible. Emphasis is placed upon the structured and graphical nature of roadmapping. The key patterns of data distribution on the roadmapping canvas identify potential sources of foresight evidence failure. Hence, the roadmapping canvas provides a diagnostic function to examine the sufficiency, efficacy, and credibility of strategic foresight evidence. The implications for roadmapping practice are five principles for adaptive roadmapping to be added to methodological guidelines.

\section{Conclusions}

A review of futures and foresight methods focusing on forecasting, scenarios, and roadmapping has been provided. Critical questions for the future development of methodology in futures and foresight have been offered. A series of important papers furthering methodological developments in this field have been introduced. Daim et al. and Lee et al. show how data-driven approaches can support data collection and knowledge generation. Such methods provide the potential to augment people's creativity in generating new knowledge about the future. Velasco et al. and O'Sullivan et al. clarify the critical relationship between knowledge generation and the outputs of futures and foresight activities. Velasco et al. and O'Sullivan et al. provide useful guidance to improve how better outputs are obtained from futures studies. Murata et al. promote stakeholder engagement enabling diversified knowledge and identifies what needs to be better exploited. These five contributions address many concerns with the questions of: 
- To what can extent digital technologies, artificial intelligence (AI), and other data-driven approaches support and enhance futures and foresight activities?

- What are the prerequisites for maximizing the benefits of utilizing the outputs of futures and foresight activities in order to solve the problem being addressed?

- Which part of the futures and foresight process can more diversified and personalized to reflect needs in society and/or on the market? Exactly how will this be achieved?

Nevertheless, there is still a need for the consideration of the following important questions:

- To what extent can the outputs of futures and foresight activities be evaluated before implementation (i.e., prior to Step IV)?

- How can decision-making be supported in a more agile and appropriate manner? How is this impacted by market competitiveness?
- As sustainability is increasingly important, what sort of methods and techniques help to generate useful knowledge to cover a longer time horizon (e.g., 2050 or 2060)?

- How should futures and foresight methods be adjusted or adapted in the future due to the impacts of Covid-19 (given that the pandemic has caused a drastic change in people's workstyles relating to the use of virtual environments)?

Finally, as futures and foresight are fundamentally transdisciplinary in terms of not only the topics considered, but both the inputs and outputs, there is a strong need to involve researchers and practitioners from diverse disciplines. Once such an approach is fully understood, futures and foresight methodologies can be utilized to their full potential for the consideration of more micro issues (organizational concerns), broader economics (sectoral or geographic concerns), and grand challenges (global concerns).

\section{References}

Amer M., Daim T.U., Jetter A. (2013) A review of scenario planning. Futures, 46, 23-49. https://doi.org/10.1016/j.futures.2012.10.003

Armstrong J.S. (2001) Principles of forecasting: A handbook for researchers and practitioners, Dordrecht Kluwer Academic Publishers.

Bass F.M. (1969) A new product growth model for consumer durables. Management Science, 15(5), 215-227. http://www.jstor.org/stable/2628128

Bishop P., Hines A., Collins T. (2007) The current state of scenario development: An overview of techniques. Foresight, 9(1), 5-25. https://doi. org/10.1108/14636680710727516

Börjeson L., Höjer M., Dreborg K.H., Ekvall T., Finnveden G. (2006) Scenario types and techniques: Towards a user's guide. Futures, 38(7), 723-739. https://doi.org/10.1016/j.futures.2005.12.002

Bradfield R., Wright G., Burt G., Cairns G., van der Heijden K. (2005) The origins and evolution of scenario techniques in long range business planning. Futures, 37(8), 795-812. https://doi.org/10.1016/j.futures.2005.01.003

Carayannis E., Grebeniuk A., Meissner D. (2016) Smart roadmapping for STI policy. Technological Forecasting and Social Change, 110, $109-116$. https://doi.org/10.1016/j.techfore.2015.11.003

Chen K., Ren Z., Mu S., Sun T.Q., Mu R. (2020) Integrating the Delphi survey into scenario planning for China's renewable energy development strategy towards 2030. Technological Forecasting and Social Change, 158, 120157. https://doi.org/10.1016/j.techfore.2020.120157

Culot G., Orzes G., Sartor M., Nassimbeni G. (2020) The future of manufacturing: A Delphi-based scenario analysis on Industry 4.0. Technological Forecasting and Social Change, 157, 120092. https://doi.org/10.1016/j.techfore.2020.120092

Daim T.U., Oliver T. (2008) Implementing technology roadmap process in the energy services sector: A case study of a government agency. Technological Forecasting and Social Change, 75(5), 687-720. https://doi.org/10.1016/j.techfore.2007.04.006

De Alcantara D.P., Martens M.L. (2019) Technology Roadmapping (TRM): A systematic review of the literature focusing on models. Technological Forecasting and Social Change, 138, 127-138. https://doi.org/10.1016/j.techfore.2018.08.014

Fan Z.P., Che Y.J., Chen Z.Y. (2017) Product sales forecasting using online reviews and historical sales data: A method combining the Bass model and sentiment analysis. Journal of Business Research, 74, 90-100. https://doi.org/10.1016/j.jbusres.2017.01.010

Fenwick D., Daim T.U., Gerdsri N. (2009) Value Driven Technology Road Mapping (VTRM) process integrating decision making and marketing tools: Case of Internet security technologies. Technological Forecasting \& Social Change, 76, 1055-1077. https://doi.org/10.1016/j. techfore.2009.04.005

Fergnani A., Chermack T.J. (2021) The resistance to scientific theory in futures and foresight, and what to do about it. Futures and Foresight Science, e61. https://doi.org/10.1002/ffo2.61

Gattringer R., Wiener M. (2020) Key factors in the start-up phase of collaborative foresight. Technological Forecasting and Social Change, 153, 119931. https://doi.org/10.1016/j.techfore.2020.119931

Gerstenfeld A. (1971) Technological forecasting. The Journal of Business, 44(1), 10-18. http://dx.doi.org/10.1086/295328

Geum Y., Lee H., Lee Y., Park Y. (2015) Development of data-driven technology roadmap considering dependency: An ARM-based technology roadmapping. Technological Forecasting and Social Change, 91, 264-279.

Glenn J.C. (2009a) Introduction. In: Futures Research Methodology (CD-ROM version 3.0) (eds. J.C. Glenn, T.J. Gordon), Washington, D.C.: The Millennium Project. http://www.millennium-project.org/publications-2/futures-research-methodology-version-3-0/, accessed 15.06.2020.

Glenn J.C. (2009b) Scenarios. In: Futures Research Methodology (CD-ROM version 3.0) (eds. J.C. Glenn, T.J. Gordon), Washington, D.C.: The Millennium Project. http://www.millennium-project.org/publications-2/futures-research-methodology-version-3-0/, accessed 15.06.2020.

Gordon A.V., Ramic M., Rohrbeck R., Spaniol M.J. (2020) 50 Years of corporate and organizational foresight: Looking back and going forward. Technological Forecasting and Social Change, 154, 119966. https://doi.org/10.1016/j.techfore.2020.119966

Gordon T.J. (2009) Delphi. In: Futures Research Methodology (CD-ROM version 3.0) (eds. J.C. Glenn, T.J. Gordon), Washington, D.C.: The Millennium Project. http://www.millennium-project.org/publications-2/futures-research-methodology-version-3-0/, accessed 15.06.2020.

Gordon T.J., Glenn J.C. (2009) Environmental scanning. In: Futures Research Methodology (CD-ROM version 3.0) (eds. J.C. Glenn, T.J. Gordon), Washington, D.C.: The Millennium Project. http://www.millennium-project.org/publications-2/futures-research-methodologyversion-3-0/, accessed 15.06.2020.

Hancock T., Bezold C. (1994) Possible futures, preferable futures. The Healthcare Forum Journal, 37(2), 23-29. https://pubmed.ncbi.nlm.nih. gov/10132155/, accessed 15.06.2020.

Hussein M., Tapinos E., Knight L. (2017) Scenario-driven roadmapping for technology foresight. Technological Forecasting and Social Change, 124, 160-177. https://doi.org/10.1016/j.techfore.2017.05.005

Kahn H., Wiener A.J. (1967) The year 2000: A framework for speculation on the next thirty-three years, New York: Macmillan.

Kayser V., Blind K. (2017) Extending the knowledge base of foresight: The contribution of text mining. Technological Forecasting and Social Change, 116, 208-215. https://doi.org/10.1016/j.techfore.2016.10.017 
Kayser V., Shala E. (2020) Scenario development using web mining for outlining technology futures. Technological Forecasting and Social Change, 156, 120086. https://doi.org/10.1016/j.techfore.2020.120086

Kehl W., Jackson M., Fergnani A. (2020) Natural language processing and futures studies. World Futures Review, 12(2), 181-197. https://doi. org/10.1177\%2F1946756719882414

Kishita Y., Hara K., Uwasu M., Umeda Y. (2016) Research needs and challenges faced in supporting scenario design in sustainability science: A literature review. Sustainability Science, 11(2), 331-347. https://doi.org/10.1007/s11625-015-0340-6

Kishita Y., Kusaka T., Mizuno Y., Umeda Y. (2021) Toward theory development in futures and foresight by drawing on design theory: A commentary on Fergnani and Chermack 2021. Futures and Foresight Science, e91. https://doi.org/10.1002/ffo2.91

Kishita Y., Mizuno Y., Fukushige S., Umeda Y. (2020) Scenario structuring methodology for computer-aided scenario design: An application to envisioning sustainable futures. Technological Forecasting and Social Change, 160, 120207. https://doi.org/10.1016/j.techfore.2020.120207

Kuwahara T. (1999) Technology forecasting activities in Japan. Technological Forecasting and Social Change, 60(1), 5-14. https://doi.org/10.1016/ S0040-1625(98)00048-1

Kuwahara T., Cuhls K., Georghiou L. (2008) Foresight in Japan. In: The Handbook of Technology Foresight: Concepts and Practice (eds. L. Georghiou, J.C. Harper, M. Keenan, I. Miles, R. Popper), Cheltenham: Edward Elgar, pp. 170-183.

Lee H., Geum Y. (2017) Development of the scenario-based technology roadmap considering layer heterogeneity: An approach using CIA and AHP. Technological Forecasting and Social Change, 117, 12-24. https://doi.org/10.1016/j.techfore.2017.01.016

Lehoux P., Miller F.A., Williams-Jones B. (2020) Anticipatory governance and moral imagination: Methodological insights from a scenariobased public deliberation study. Technological Forecasting and Social Change, 151, 119800. https://doi.org/10.1016/j.techfore.2019.119800

Linstone H.A., Turoff M. (1975) The Delphi method: Techniques and applications, London: Addison-Wesley.

Maede N., Islam T. (2006) Modelling and forecasting the diffusion of innovation: A 25-year review. International Journal of Forecasting, 22(3), 519-545. https://doi.org/10.1016/j.ijforecast.2006.01.005

Martelli A. (2001) Scenario building and scenario planning: State of the art and prospects of evolution. Futures Research Quarterly, 17(2), 57-74.

Martino J.P. (1993) Technological forecasting for decision making (3 ${ }^{\text {rd }}$ ed.), New York: McGraw-Hill.

Miles I. (2010) The development of technology foresight: A review. Technological Forecasting and Social Change, 77(9), 1448-1456. https://doi. org/10.1016/j.techfore.2010.07.016

Nonaka I. (1990) Management of Knowledge Creation, Tokyo: Nihon Keizai Shinbun-sha.

Ogilvy J., Schwartz P. (1998) Plotting your scenarios. Learning from the future (eds. L. Fahey, R. Randall), Hoboken, NJ: John Wiley, pp. 57-80.

Ozcan S., Homayounfard A., Simms C., Wasim J. (2021) Technology roadmapping using text mining: A foresight study for the retail industry. IEEE Transactions on Engineering Management (early access). DOI: 10.1109/TEM.2021.3068310.

Park H., Phaal R., Ho J.Y., O'Sullivan E. (2020) Twenty years of technology and strategic roadmapping research: A school of thought perspective. Technological Forecasting and Social Change, 154, 119965. https://doi.org/10.1016/j.techfore.2020.119965

Phaal R. Farrukh C.J.P., Probert D.R. (2004) Technology roadmapping: A planning framework for evolution and revolution. Technological Forecasting and Social Change, 71(1-2), 5-26. https://doi.org/10.1016/S0040-1625(03)00072-6

Phaal R., Farrukh C., Mitchell R., Probert D. (2003) Starting-up roadmapping fast. Research-Technology Management, 42(2), 52-59. https://doi. org/10.1080/08956308.2003.11671555

Phaal R., Farrukh C.J.P., Probert D.R. (2010) Roadmapping for Strategy and Innovation: Aligning technology and markets in a dynamic world, Cambridge: University of Cambridge.

Popper R. (2008a) Foresight methodology. In: The Handbook of Technology Foresight: Concepts and Practice (eds. L. Georghiou, J.C. Harper, M. Keenan, I. Miles, R. Popper), Cheltenham: Edward Elgar, pp. 44-88.

Popper R. (2008b) How are foresight methods selected. Foresight, 10(6), 62-89. https://doi.org/10.1108/14636680810918586

Pora U., Gerdsri N., Thawesaengskulthai N., Triukose S. (2020) Data-driven roadmapping (DDRM): Approach and case demonstration. IEEE Transactions on Engineering Management (early access). DOI: 10.1109/TEM.2020.3005341

Quist J., Vergragt P. (2006) Past and future of backcasting: The shift to stakeholder participation and a proposal for a methodological framework. Futures, 38(9), 1027-1045. https://doi.org/10.1016/j.futures.2006.02.010

Rogers E. (2002) Diffusion of Innovations (5th ed.), New York: Free Press.

Rowe G., Wright G. (2011) The Delphi technique: Past, present, and future prospects (Introduction to the special issue). Technological Forecasting and Social Change, 78(9), 1487-1490. https://doi.org/10.1016/j.techfore.2011.09.002

Saritas O., Aylen J. (2010) Using scenarios for roadmapping: The case of clean production. Technological Forecasting and Social Change, 77, 1061-1075. https://doi.org/10.1016/j.techfore.2010.03.003

Schwartz P. (1991) The Art of the Long View: Planning for the Future in an Uncertain World, New York: John Wiley \& Sons, Doubleday.

Seol H., Park G., Lee H., Yoon B. (2012) Demand forecasting for new media services with consideration of competitive relationships using the competitive Bass model and the theory of the niche. Technological Forecasting and Social Change, 79(7), 1217-1228. https://doi.org/10.1016/j. techfore.2012.03.002

Siebelink R., Halman J.I.M., Hofman E. (2016) Scenario-driven roadmapping to cope with uncertainty: Its application in the construction industry. Technological Forecasting and Social Change, 110, 226-238. https://doi.org/10.1016/j.techfore.2016.01.030

Spaniol M.J., Rowland N.J. (2019) Defining scenario. Futures and Foresight Science, 1(1), e3. https://doi.org/10.1002/ffo2.3

Urashima K., Yokoo Y., Nagano H. (2012) S\&T policy and foresight investigation - Impacts in Japan. Foresight, 14(1), 15-25. https://doi. org/10.1108/14636681211210332

Van der Duin P. (ed.) (2016) Foresight in organizations: Methods and tools, New York: Routledge.

Van Notten P.W.F., Rotmans J., van Asselt M.B.A., Rothman D.S. (2003) An updated scenario typology. Futures, 35, 423-443. https://doi. org/10.1016/S0016-3287(02)00090-3

Vatananan R.S., Gerdsri N. (2012) The current state of technology roadmapping (TRM) research and practice. International Journal of Innovation and Technology Management, 9(4), 1250032. https://doi.org/10.1142/S0219877012500320

Von der Gracht H.A., Darkow I.L. (2010) Scenarios for the logistics services industry: A Delphi-based analysis for 2025. International Journal of Production Economics, 127(1), 46-59. https://doi.org/10.1016/j.ijpe.2010.04.013

Voros J. (2003) A generic foresight process framework. Foresight, 5(3), 10-21. https://doi.org/10.1108/14636680310698379

Wack P. (1985) Scenarios: Uncharted waters ahead. Harvard Business Review, 63, 73-89.

Wilkinson A. (2009) Scenarios practices: In search of theory. Journal of Futures Studies, 13, 107-114.

Willyard C.H., McClees C.W. (1987) Motorola’s technology roadmap process. Research Management, 30(5), 13-19. https://doi.org/10.1080/00 345334.1987.11757057

Wright G., Cairns G., Bradfield R. (2013) Scenario methodology: New developments in theory and practice (Introduction to the Special Issue). Technological Forecasting and Social Change, 80, 561-565. https://doi.org/10.1016/j.techfore.2012.11.011

Yasunaga Y., Watanabe M., Korenaga M. (2009) Application of technology roadmaps to governmental innovation policy for promoting technology convergence. Technological Forecasting and Social Change, 76(1), 61-79. https://doi.org/10.1016/j.techfore.2008.06.004

Zhou Y., Dong F., Liu Y., Li Z., Du J.F., Zhang L. (2020) Forecasting emerging technologies using data augmentation and deep learning. Scientometrics, 123, 1-29. https://doi.org/10.1007/s11192-020-03351-6 